\title{
COMPARISON OF RADIOCARBON AGES FROM DIFFERENT ORGANIC FRACTIONS IN TROPICAL PEAT CORES: INSIGHTS FROM KALIMANTAN, INDONESIA
}

\author{
Raphael A J Wüst ${ }^{1} \cdot$ Geraldine E Jacobsen ${ }^{2}$ Haitse van der Gaast ${ }^{2} \bullet$ Andrew M Smith $^{2}$
}

\begin{abstract}
Various organic fractions of an Indonesian tropical peat deposit were dated using radiocarbon accelerator mass spectrometry (AMS). Four different depth layers, deposited during the last $28,000{ }^{14} \mathrm{C}$ yr, were analyzed and the data compared to bulk sample analyses. The pollen extracts consistently produced the oldest dates. The bulk samples $(<250 \mu \mathrm{m}$ and $<100 \mu \mathrm{m}$ ) often yielded the youngest dates. The age difference between the individual fractions depended on the layer depth and hence the true age of the sampled peats. The age discrepancy was highest $\left(\sim 16,000{ }^{14} \mathrm{C}\right.$ yr $)$ in the oldest peat material. We interpret this to be a consequence of the input of organic matter over a long period of time, with peat oxidation and/or no peat accumulation during the last glacial maximum (LGM). The age discrepancies were smaller (between 10 and $900{ }^{14} \mathrm{C} \mathrm{yr}$ ) for the Holocene peat samples. It was concluded that the pollen extract fraction might be the most reliable fraction for dating tropical peat deposits that are covered by deeply rooting vegetation.
\end{abstract}

\section{INTRODUCTION}

During the last 3 decades, many studies have focused on peatlands and peat deposits in order to assess paleoenvironmental changes or anthropogenic impact during the Holocene (Casagrande and Erchull 1977; Shotyk 1988; Shotyk et al. 1998; Blackford 2000). Peat deposits are sensitive archives of environmental changes provided they have a convex topography, and therefore receive only atmospheric inorganic influx (Shotyk et al. 1998). These deposits are also ideal for paleobotanical studies.

The determination of the "average" age of a single layer is often based on either the bulk material or one or more biological components (e.g. coral fragments, shells, leaves, pollen, etc.). Time-averaging determines the length of time represented by a stratigraphic layer but limits the temporal resolution of a given record (Flessa et al. 1993). The underlying true age of interest is the unknown age distribution of all biological constituents within a sedimentary layer. Time-averaging is fundamentally determined by 3 largely independent parameters: 1) the rate of sediment accumulation; 2) the characteristics of sediment mixing; and 3) the durability of the individual constituents being averaged. The sedimentation rate determines the minimum possible degree of time-averaging. Generally, higher rates of sedimentation lead to less time-averaging. The rate and depth of mixing determine the maximum possible degree of time-averaging, with deeper and faster sediment mixing leading to more time-averaging.

Classical sedimentary archives, such as lake deposits, are generally deposited sequentially forming distinct stratigraphic layers. Although stratigraphic layers are also recognized in peat deposits, their formation differs from classical lake deposits. Peat deposits are waterlogged soils composed mainly of organic materials derived from both the surface (e.g. leaves, pollen, bark, diatoms, insect fragments, airborne charcoal, branches, pollen, spores, macrofossils, etc.) and the subsurface (roots, macrofossil and microbial remains). The most abundant peatlands, i.e. temperate peatlands of high latitudes or high (>1500 m) elevations, are dominated by mosses and shrubs that have short roots, and therefore most of their subsurface input occurs just underneath the surface layer. In contrast, most tropical lowland peatlands, accounting for $\sim 12 \%$ of the global peatlands (Rieley et al. 1996), host rainforest vegetation that has mostly shallow (up to $80 \mathrm{~cm}$ ) but also some deep $(>150 \mathrm{~cm}$ ) root systems. In such cases, subsurface input of root material has been estimated to be as high as $90 \%$ of the

\footnotetext{
${ }^{1}$ School of Earth and Environmental Sciences, James Cook University, Townsville QLD 4811, Australia. Corresponding author. Email: raphael.wust@jcu.edu.au.

${ }^{2}$ Institute for Environmental Research, ANSTO, PMB 1, Menai NSW 2234, Australia.
} 
total organic matter (Ruppert et al. 1993; Wüst and Bustin 2003). Most of this accumulates in the acrotelm layer. The acrotelm layer ( $\sim$ top $50 \mathrm{~cm}$, but this can range from $<20$ to $>100 \mathrm{~cm}$ ) is defined as the top peat layer that may be aerated during parts of the year as a result of a fluctuating water table.

Interpretation of paleoenvironmental data in peat deposits and lake sediments requires establishment of a reliable chronology for the stratigraphic layers (or "units"). This is often determined by dating organic fractions using radiocarbon techniques, either by radiometric dating or accelerator mass spectrometry (AMS). There have been many studies investigating methods for improving chronologies of peat and lake sedimentary archives, these studies have focused on a) identifying the material most appropriate for dating (e.g. bulk organics vs. macrofossils, pollen concentrates) (e.g. Björck et al. 1998; Vandergoes and Prior 2003; Oswald et al. 2005; Zhou et al. 2005) and removal of contamination (Goh 1978; Cook et al. 1998) and b) development of age models to establish agedepth relationships (Telford et al. 2004).

In peatland studies, many investigations utilize "bulk" peat material that provides ${ }^{14} \mathrm{C} /{ }^{12} \mathrm{C}$ and ${ }^{13} \mathrm{C} /$ ${ }^{12} \mathrm{C}$ signatures based on "averaged" signatures of all the individual components within the sample. This can lead to an underestimation of the age of the layer due to a surface biomass input into the subsurface layers. Initially, ${ }^{14} \mathrm{C}$ investigations attempted to reduce the severity of the problem by wet sieving the peat and dividing it into coarse and fine fractions prior to standard pretreatment (Nilsson et al. 2001; Zhou et al. 2005). The coarse fraction is more likely to incorporate non-contemporaneous intrusive rootlets. Alternatively, specific components, such as macrofossils or pollen, can be isolated from the sediments, often involving a complex series of chemical treatments and physical separations (Brown et al. 1992; Sarmaja-Korjonen et al. 2003). Zhou et al. (2005) found that there was no significant difference in the ages of the pollen extract and the sieved pretreated peat, though both were significantly older than the bulk pretreated material (not sieved), which was 4000 yr younger. This approach assumes that the pollen fraction represents the "time of deposition," although a study testing the vertical movement of pollen and spores showed that these constituents may experience marked vertical movements under certain flow regimes (Clymo and Mackay 1987). A few studies have been able to assess the ${ }^{14} \mathrm{C}$-dated material against independent chronological markers such as tephra-layer ages (Cook et al. 1998; Newnham et al. 2007).

In tropical peat deposits, many ${ }^{14} \mathrm{C}$ records contain significant "age inversions" where younger ${ }^{14} \mathrm{C}$ ages occur below older ages (e.g. Page et al. 2004). This is often the result of the young carbon input through root systems, but some organic fractions may also flow through the deposits and are therefore not contemporaneous. Mobile organic remains may move up or down the profile in peat environments (Clymo and Mackay 1987) under neutral conditions. Most modern peat environments are, however, slightly acidic to acidic. Under acidic conditions, humic acid solubility is low, and hence bulk transport of the humic acids between layers is restricted. This fraction then more closely reflects the age of the layer than other peat components. Some studies have preferentially separated this fraction during pretreatment for dating purposes (Cook et al. 1995; Xu and Zheng 2003).

Pretreatment methods are carried out to remove extraneous, contaminating components that, if not eliminated, would result in incorrect ${ }^{14} \mathrm{C}$ dates (Gupta and Polach 1985; Nilsson et al. 2001) as the analysis will comprise multiple components of differing ages (Hedges 1992). Often, by isolating an individual component or specific fraction (e.g. macrofossil, pollen), contaminating carbon can be identified and removed. For example, a study comparing neighboring peat cores and 3 different fractions (humic acids, humins, and fulvic acids) produced ${ }^{14} \mathrm{C}$ ages for the humic acids that were up to $>1200 \mathrm{yr}$ older than the humin fraction from the same layer (Shore et al. 1995). Although these chemical sample pretreatment protocols appear straightforward, the separation of the individual components is often much more difficult and involves significant time and resource commitments. 
Successful pretreatment of peat material alone does not ensure that the ${ }^{14} \mathrm{C}$ date will represent the time event of interest (e.g. Nilsson et al. 2001; Xu and Zheng 2003). Sample integrity is also a factor. Sample integrity can be affected by factors such as the old-wood effect, bioturbation, secondary deposition, and secondary biogenic activity incorporating recent carbon (bacteria and fungi).

Some studies have looked at "age inhomogeneities" within layers using bulk peat material of large core intervals (e.g. milled and mixed 20-cm core sections; Page et al. 2004) or separated specific fractions, such as bark or pollen extracts (e.g. Anshari et al. 2004). These have been focused on determining solid chronological time frames of the deposits rather than on developing an understanding of time-averaging in peatlands. Those studies that have compared the significance of different plant material or fractions of peats for chronostratigraphic models (e.g. Cook et al. 1998; Nilsson et al. 2001) have been done on temperate peats. No comparative studies have been undertaken on tropical peats, which are significantly different in both peat composition and vegetation (due to the nature of the rainforest coverage).

In 2005, we investigated a tropical peat core from Kalimantan, Indonesia, performing ${ }^{14} \mathrm{C}$ dating on the bulk peat material. This peat had undergone the conventional acid-alkali-acid (AAA) pretreatment, removing fulvic and humic acids, and the residual insoluble organic material (humins) was dated. Prior to the chemical pretreatment, all samples had been sieved through a $250-\mu \mathrm{m}$ sieve and rootlets removed by hand under the microscope. Microscopic analyses of the pretreated materials showed various constituents such as charcoal fragments, biogenic silica fragments of roots, long and fragmented short rootlets, bark fragments, seeds, spores, etc. (Figure 1). The visual inspection also revealed quite abundant thin but long (up to $15 \mathrm{~mm}$ ) carbonized rootlets and intact rootlets. Although it is well known that peat deposits from the tropics are dominated by root biomass, the different rootlet characteristics (i.e. carbonized, short fragmented, etc.) implied that differently aged material was most likely present. The resulting bulk ${ }^{14} \mathrm{C}$ ages from the Kalimantan peat core showed several significant "age inversions." As a consequence, new sample material was selected and several individual fractions were separated (pollen, seeds, bark fragments, etc.), and the ${ }^{14} \mathrm{C}$ age of each fraction was determined. A fine-grained bulk sample $(<100-\mu \mathrm{m}$ sieve size) was also prepared, and was expected to contain mainly highly degraded organic material.

In this study, we assessed the applicability of ${ }^{14} \mathrm{C}$ dating applied to 3 to 4 different fractions (bulk organics, pollen, macrofossils) of 4 individual peat layers in order to determine the age model and any age profiling inconsistencies associated with tropical peats from a central Kalimantan peat dome. The study discusses possible errors, implications for age models, and provides recommendations for future applications of ${ }^{14} \mathrm{C}$ dating in tropical peat environments. It provides an insight into time-averaging within tropical peatlands.

\section{METHODS}

The peat material used for the investigations was selected from a 950-cm-long peat core (Kal-1, Sungai Sebangau area; $\left.2^{\circ} 23.067^{\prime} \mathrm{S}, 113^{\circ} 51.791^{\prime} \mathrm{E}\right)$ from central Kalimantan, Indonesia. The peat core was collected using a D-section corer with $4.5 \mathrm{~cm}$ diameter and $50 \mathrm{~cm}$ length. The core contains peat material at various stages of decomposition. The core has an age range between 0-35,000 cal yr BP (Figure 2). This was established in a previous study of a nearby peat core located within the same peat dome $<3 \mathrm{~km}$ away (Weiss et al. 2002). The sample material was cut into 10 -cm sections and freeze-dried. Two- to 4-cm-thick sections were cut from the core for individual sample preparations at sample depths $263-265,500-504,702-705$, and 864-867 cm. A small fraction of each was set aside for pollen extraction. The 4 samples were then visually inspected under a microscope for 


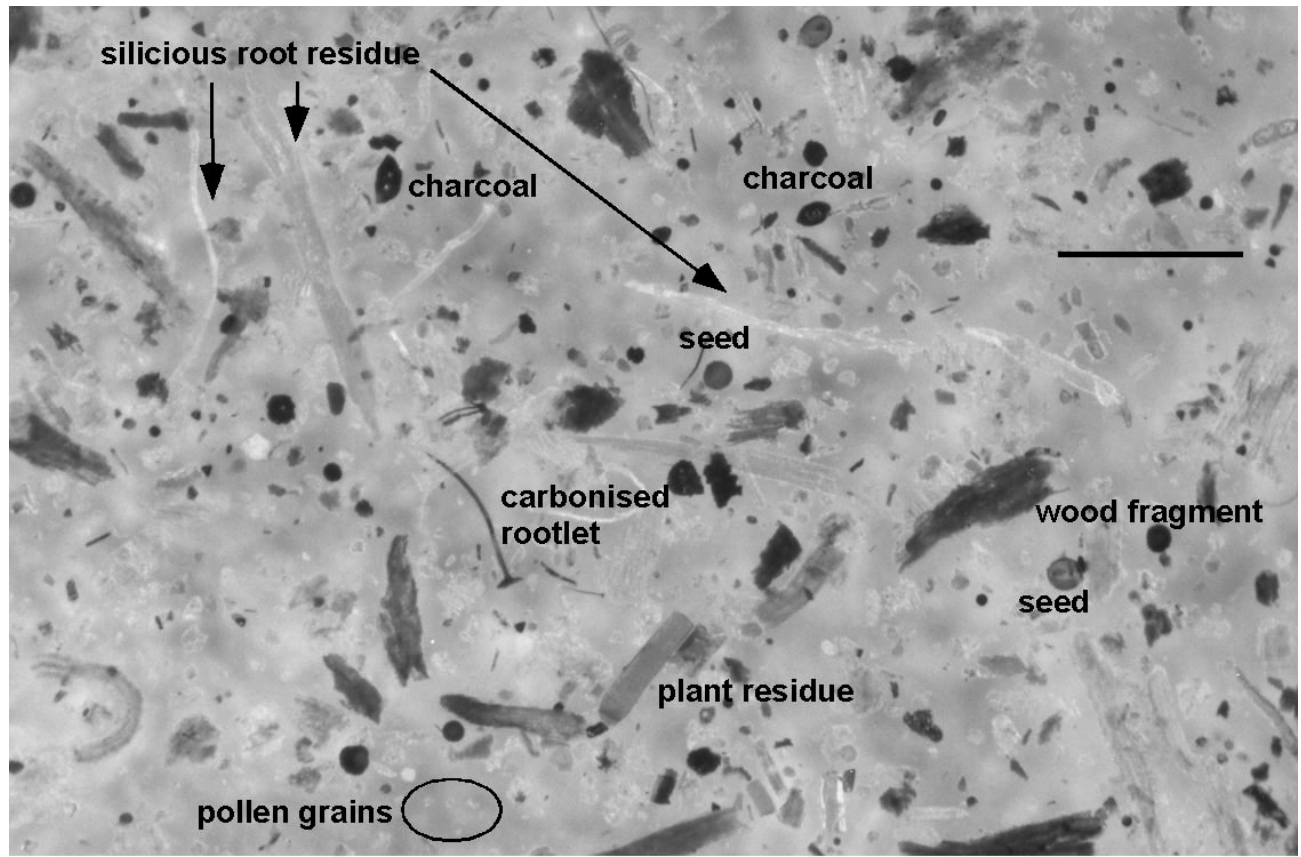

Figure 1 A representative sample from the peat core Kal- 1 at $436-437 \mathrm{~cm}$ depth that has undergone an acid-baseacid pretreatment, illustrating the complexity of constituent composition after sieving $(250 \mu \mathrm{m})$ and handpicking rootlets. Scale bar is approximately $40-50 \mu \mathrm{m}$.

macrofossils suitable for dating. An amber fragment $(263 \mathrm{~cm})$, a large charred plant fragment (263 $\mathrm{cm})$, a spine of a pandan screw pine-palm and a seed $(500 \mathrm{~cm})$, as well as 2 bark fragments $(702$ and $864 \mathrm{~cm}$ ) were selected. The remaining sample material was then sieved through a $100-\mu \mathrm{m}$ sieve and the fraction labeled as bulk material.

The pollen fractions were prepared at Monash University, Australia, by Ms U Pietrzak, according to a modified method of Kummel and Raup (1965). Sample material was soaked in a large excess of $10 \% \mathrm{Na}_{4} \mathrm{P}_{2} \mathrm{O}_{7}$ to assist particle separation. Humic acids were removed using a $10 \% \mathrm{KOH}$ solution for approximately $20 \mathrm{~min}$ at $80^{\circ} \mathrm{C}$. The samples were sieved through standard $210 \mu \mathrm{m}$ then $7 \mu \mathrm{m}$ meshes and the $210-$ to $7-\mu \mathrm{m}$ fraction washed then treated using a $10 \% \mathrm{HCl}$ solution to remove carbonates. The washed samples were then oxidized using Schultz reagent (i.e. $\mathrm{KClO}_{3}$ and $\mathrm{HNO}_{3}-$ $35 \%$ with a ratio of 1:10) for $60 \mathrm{~min}$ and then washed with a $5 \% \mathrm{NH}_{4} \mathrm{OH}$ (ammonia) solution. Heavy liquid separation of the fractions was carried out using sodium polytungstate with a specific gravity of 2. The washed sample fractions were covered in HF overnight to reduce as much silicate as possible from the sample. The samples were then washed with a $10 \% \mathrm{HCl}$ solution and then with $\mathrm{H}_{2} \mathrm{O}$. The samples were stored in $\mathrm{H}_{2} \mathrm{O}$ prior to graphitization and subsequent $\mathrm{AMS}{ }^{14} \mathrm{C}$ analysis at ANSTO.

The remaining samples underwent chemical pretreatment at ANSTO. Degradation products such as humic and fulvic acids were removed using the standard AAA method (Gupta and Polach 1985). All samples (except the pollen fractions described above) were initially washed in hot $10 \% \mathrm{HCl}$ overnight and then rinsed with deionized water to neutral $\mathrm{pH}$. Following this, the sample was treated with $2 \% \mathrm{NaOH}$ solution, heated to $80{ }^{\circ} \mathrm{C}(30 \mathrm{~min})$, then rinsed. The alkali insoluble fraction was then acidified to remove any atmospheric $\mathrm{CO}_{2}$ dissolved in the alkali solution, and rinsed thor- 


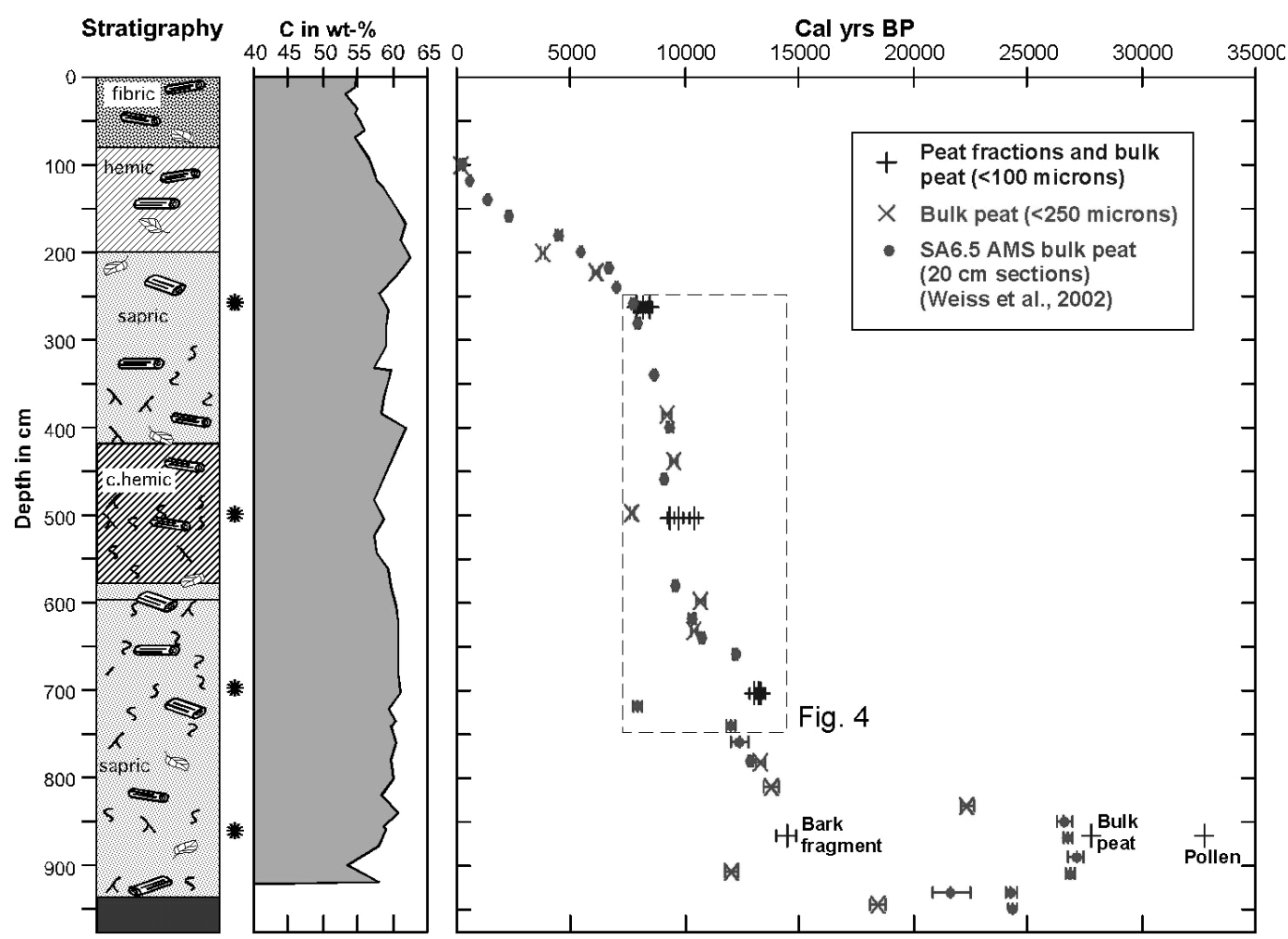

Figure 2 Stratigraphy (degree of humification) of core Kal-1, C content, and age model (cal BP). Box represents section in Figure 4.

oughly. After drying overnight, the pretreated material was combusted to carbon dioxide at $900{ }^{\circ} \mathrm{C}$ in sealed silica tubes containing $\mathrm{CuO}$, along with $\mathrm{Ag}$ and $\mathrm{Cu}$ wire to remove sulphur and nitrogen containing compounds, respectively. The $\mathrm{CO}_{2}$ was converted into graphite by reduction over iron catalyst at $600{ }^{\circ} \mathrm{C}$ using an excess of hydrogen.

The resulting target was prepared by pressing the graphitized samples into aluminium cathodes and analyzed at the AMS facility at ANSTO (Hua et al. 2001, 2004; Smith et al. 2007). An EA-IRMS determined the $\delta^{13} \mathrm{C}$ of the graphite. The ${ }^{14} \mathrm{C}$ dates were calibrated using IntCal04 (Reimer et al. $2004)$ and the calibrated age range values given $(1 \sigma$ and $2 \sigma)$, except for the 2 oldest ages (OZJ341, OZJ342) that were calibrated using Fairbanks0805 (Fairbanks et al. 2005).

\section{RESULTS}

The measured ${ }^{14} \mathrm{C}$ ages, $\delta{ }^{13} \mathrm{C}$ values, and the calibrated ${ }^{14} \mathrm{C}$ ages (including $1-$ and $2-\sigma$ intervals) for the samples are listed in Table 1. The top section contains data that were obtained during the initial investigations (sieved through a $<250-\mu \mathrm{m}$ sieve) and the bottom section shows the data obtained from the different fractions of the 4 layers. The stable carbon isotope ratios for the peat fractions vary from -26.6 to $-31.0 \%$. In general, the basal peat layer contains the heaviest $\delta^{13} \mathrm{C}$ isotope values $(-26.6$ to $-27.0 \%$ ) and the fractions above had slightly lighter values up to $-31.0 \%$ o for a charred fragment at $263-265 \mathrm{~cm}$, although the amber fragment in that layer has a $\delta^{13} \mathrm{C}$ value of $-26.8 \%$. 


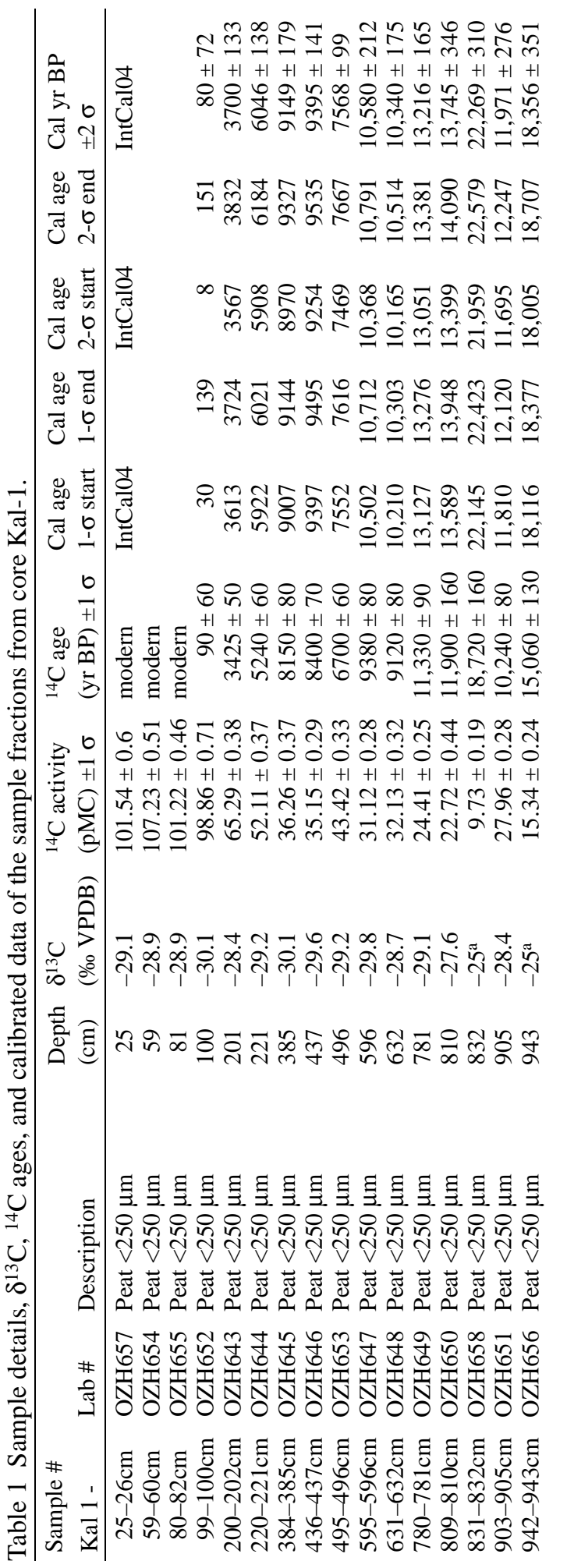

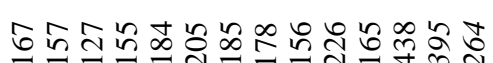
$+1+1+1+1+1+1+1+1+1+1+1+1+1+1$ ฉ

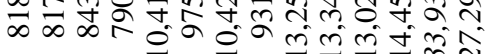

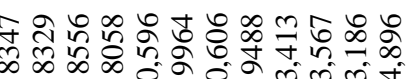

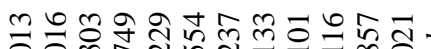
क्ष

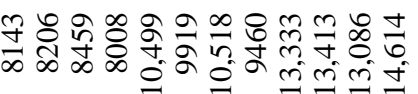

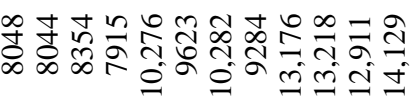

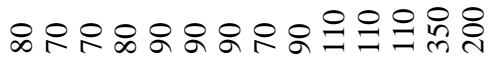
$+1+1+1+1+1+1+1+1+1+1+1+1+1+1$

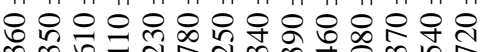

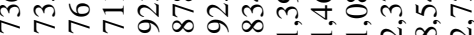

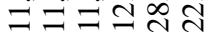

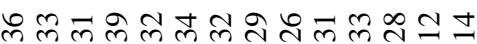

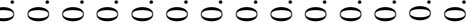
$+1+1+1+1+1+1+1+1+1+1+1+1+1+1$

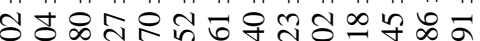

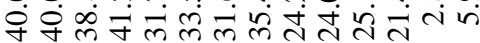

mo-m nanmant o o a

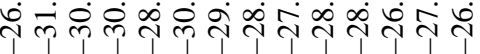

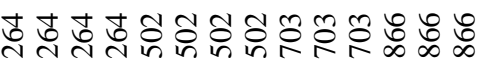

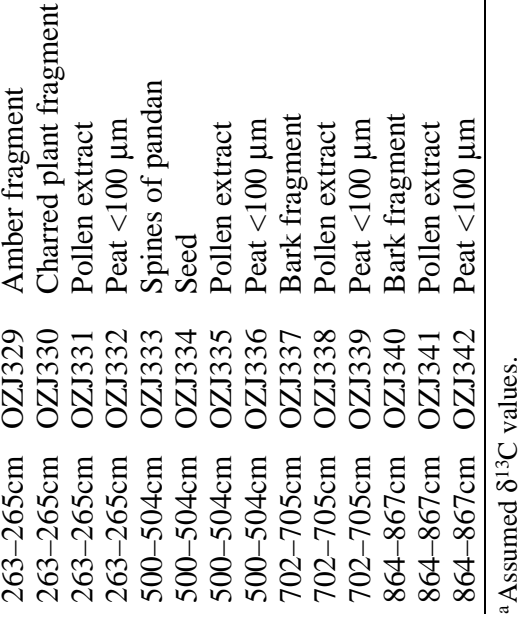


Figure 2 illustrates the stratigraphic composition, which shows changing degrees of humification of the organic material throughout the profile. Most of the peat core is highly degraded (sapric) with the top peat deposit ( top $75 \mathrm{~cm}$ ) showing the least degraded composition (fibric). The total carbon content is high throughout the core (mostly $>55 \mathrm{wt} \%$ ) and reaches values $>60 \mathrm{wt} \%$ (i.e. $\sim 200 \mathrm{~cm}$ depth). The calibrated data $(2 \sigma)$ of the 30 AMS ages obtained from core Kal-1 (Table 1) and the 29 AMS ages of the core nearby (Weiss et al. 2002) are also illustrated. The age-depth plot of the core shows that the uppermost $100 \mathrm{~cm}$ yields exclusively young, including several modern, ${ }^{14} \mathrm{C}$ ages (Table 1). All data within the top $100 \mathrm{~cm}$ represent bulk material; unfortunately, no pollen extracts of the shallow core material were analyzed. The top $230 \mathrm{~cm}$ appear to have been accumulated over the last $\sim 6000 \mathrm{cal} \mathrm{BP}$, which equates to an average accumulation rate of $\sim 0.4 \mathrm{~mm} / \mathrm{yr}$. The age model shows that the middle part of the core, between $\sim 230-810 \mathrm{~cm}$, experienced rapid $(\sim 0.8 \mathrm{~mm} / \mathrm{yr})$ and continuous accumulation of organic material that occurred between 6000-13,000 cal BP. Below 810 $\mathrm{cm}$ depth, the age of the peat material shows a large age range from about 12,000 to 35,000 cal BP. The "average" age and its accumulation rate are difficult to determine.

Figure 3 displays the ages of the individual fractions of the 4 layers investigated. Although the focus will be on the calibrated ages (1- and 2- $\sigma$ intervals), the uncalibrated age distribution (with 1 standard deviation) is also plotted. The ${ }^{14} \mathrm{C}$ ages of the different organic fractions of the 4 layers from the 9.5-m-thick peat deposit from central Kalimantan deviate from a few hundred to several thousand years from each other (Figure 3). All ${ }^{14} \mathrm{C}$ ages are older than $7000 \mathrm{BP}$ but younger than 29,000 BP. The calibrated ages $(2 \sigma)$ range from $8329-33,930 \mathrm{cal}$ BP.
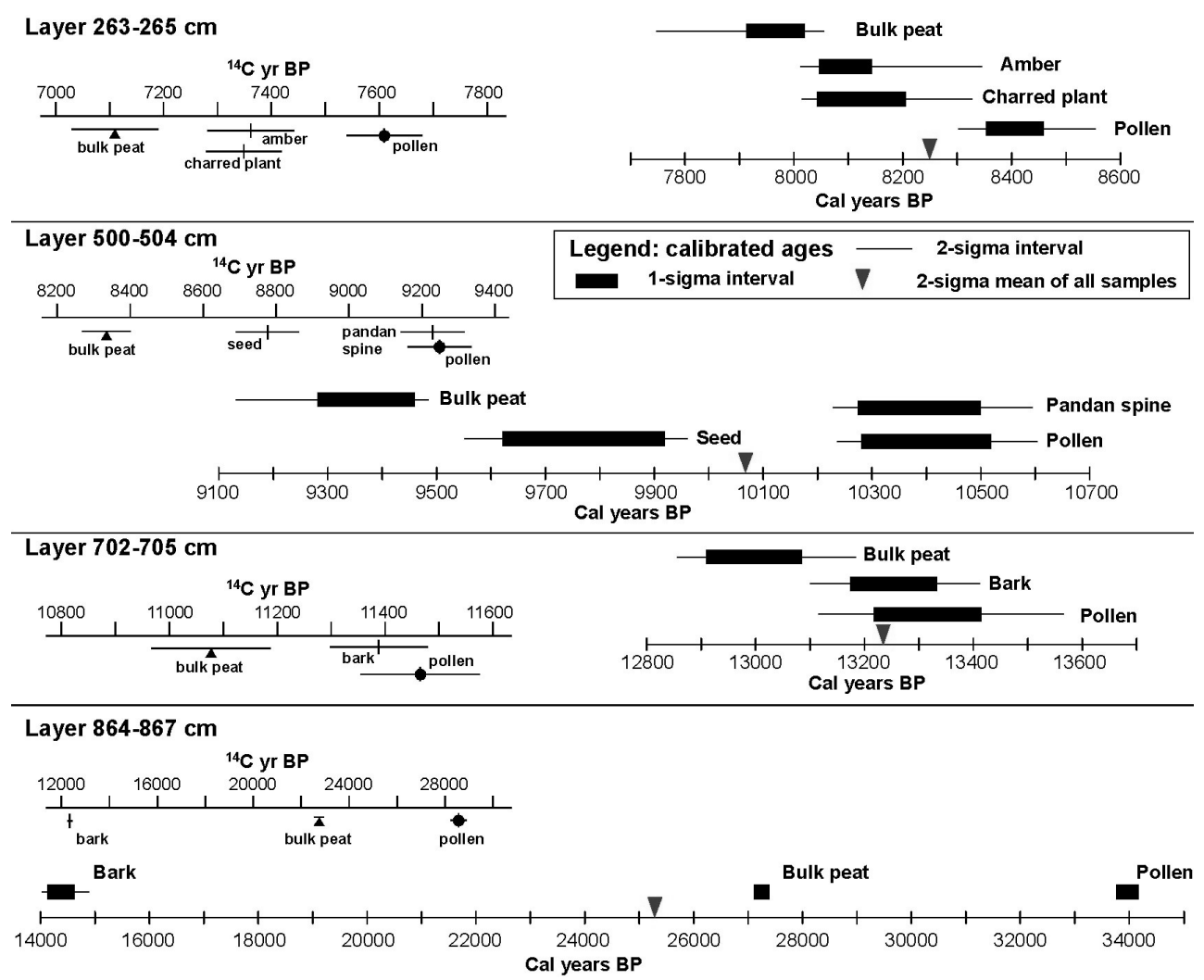

Figure $3{ }^{14} \mathrm{C}$ ages and standard deviations $(2 \sigma)$ as well as calibrated ages (1- and 2- $\sigma$ intervals) of the selected fractions of the individual peat layers from the tropical peat dome of central Kalimantan. Note the large age discrepancy in the deepest peat layer almost at the base of the 950-cm-long core. 
In the shallowest layer (263-265 cm depth), all 4 ages are very similar with overlapping 2- $\sigma$ age ranges between the amber, charred fragment and the pollen fraction (Figure 3 ). The bulk peat has the youngest age (7749-8058 cal BP; $2 \sigma$ ), followed by the amber and charred fragment (almost identical ages), whereas the pollen fraction has the oldest age (8303-8556 cal BP). The "average" of all those ages would yield an age of $8247 \pm 498 \mathrm{cal} \mathrm{BP}(2 \sigma)$.

In the deeper layer, at 500-504 $\mathrm{cm}$ depth, the age range between the selected fractions is markedly larger. The bulk peat fraction again provided the youngest age (9133-9488 cal BP), while the pandan spine $(10,229-10,596 \mathrm{cal} \mathrm{BP})$ and the pollen fraction $(10,237-10,606 \mathrm{cal} \mathrm{BP})$ have a very similar (and older) age. The seed has an age in between the bulk and pollen fractions (Figure 3). The "average" age calculated based on those 4 samples would be 10,070 $\pm 536 \mathrm{cal}$ BP $(2 \sigma)$.

In layer 702-705 cm, 3 individual fractions were analyzed and they yielded very similar ages. Again, the bulk peat showed the youngest age $(12,857-13,186 \mathrm{cal} \mathrm{BP})$, whereas the bark fragment and the pollen samples had nearly identical ages $(13,101-13,413$ and $13,116-13,567 \mathrm{cal} \mathrm{BP}$, respectively). The calculated mean of these 3 ages yields an age of 13,298 \pm 441 cal BP $(2 \sigma)$.

Three fractions were analyzed from the lowermost layer (864-867 cm depth): a bark fragment, bulk peat, and the pollen concentrate (Table 1). The bark produced the youngest age at 14,021-14,896 cal BP $(2 \sigma)$. The bulk peat yielded an age of 27,290 \pm 264 cal BP $(2 \sigma$, Fairbanks0805) and the pollen concentrates and age of $33,930 \pm 395 \mathrm{cal} \mathrm{BP}(2 \sigma$, Fairbanks0805). This layer is part of the peat profile that developed during the LGM and hence contains a mixture of younger carbon material from the vegetation growth during the early Holocene and significant older carbon from the last glacial period. The calculated mean of these 3 ages yields an age of 25,299 $\pm 11,278$ cal BP (2 $\sigma)$, which has a large standard deviation.

In summary, within the 4 layers investigated, the pollen concentrates gave the oldest ${ }^{14} \mathrm{C}$ ages, while the bulk peat samples represented the "youngest" ages, except for the deepest layer where the bark fragment was considerably younger $\left(\sim 13,000{ }^{14} \mathrm{C}\right.$ yr) than the bulk peat material. There, an age difference of $\sim 5500{ }^{14} \mathrm{C}$ yr was also noted between the bulk and the pollen fraction (Table 1, Figure 3). In the uppermost layer (263-265 cm depth, $\sim 8000 \mathrm{cal} \mathrm{BP})$, the age difference between the bulk material and the pollen extract was $\sim 500{ }^{14} \mathrm{C}$ yr, while both charred plant fragment and the amber fragment were only $\sim 250{ }^{14} \mathrm{C}$ yr younger than the pollen extract. In the deeper section, at 500-504 $\mathrm{cm}$ depth $(\sim 10,000 \mathrm{cal} \mathrm{BP})$, the age difference between the bulk peat and the pollen extract was almost $1000{ }^{14} \mathrm{C}$ yr. In that layer, the pandan spine fragment and the pollen extract have almost identical ages, whereas the age difference between the seed and the pollen extract was $\sim 470{ }^{14} \mathrm{C}$ yr. The smallest age difference between the oldest and youngest fragments was found in the layer at 702$705 \mathrm{~cm}$ depth $(\sim 13,000 \mathrm{cal} \mathrm{BP})$, where the difference between bulk and pollen fraction was $\sim 400{ }^{14} \mathrm{C}$ yr (Figure 3).

For a better understanding of the age discrepancies, "time-averaging," and the age models of tropical peats, the middle section of the core (250-750 cm depth) was plotted in detail (Figure 4). Our data (layers: 263-265, 500-504, 702-705 cm) are presented together with the data from the bulk analysis from the first part of this study $(<250-\mu \mathrm{m}$ size fraction with hand-removed rootlets) (Table 1 ) and the bulk age samples (20-cm intervals milled, not sieved) from the nearby core SA6.5 of the same peat dome (Weiss et al. 2002). The calibrated ages show a somewhat coherent age model where the peat becomes progressively younger with decreasing depth. In general, the bulk peat samples have younger ages than the individual fractions, and so the individual fractions or pollen extracts would result in a slightly older age model for the peat core. In the shallowest depths, around $260 \mathrm{~cm}$ depth, the age difference between the fractions and core SA6.5 are very small $\left(\sim 100{ }^{14} \mathrm{C} \mathrm{yr}\right.$ 
between bulk peat and SA6.5 samples). Between 260 and $500 \mathrm{~cm}$ depth, the bulk peat samples become progressive older. At a depth of $\sim 500 \mathrm{~cm}$, the bulk peat $(<250 \mu \mathrm{m})$ and fine bulk peat $(<100 \mu \mathrm{m})$ exhibited a considerable age difference $\left(\sim 2300{ }^{14} \mathrm{C} \mathrm{yr}\right)$ and the pollen fraction is $\sim 1000{ }^{14} \mathrm{C}$ yr older than the fine bulk material (Figure 4).

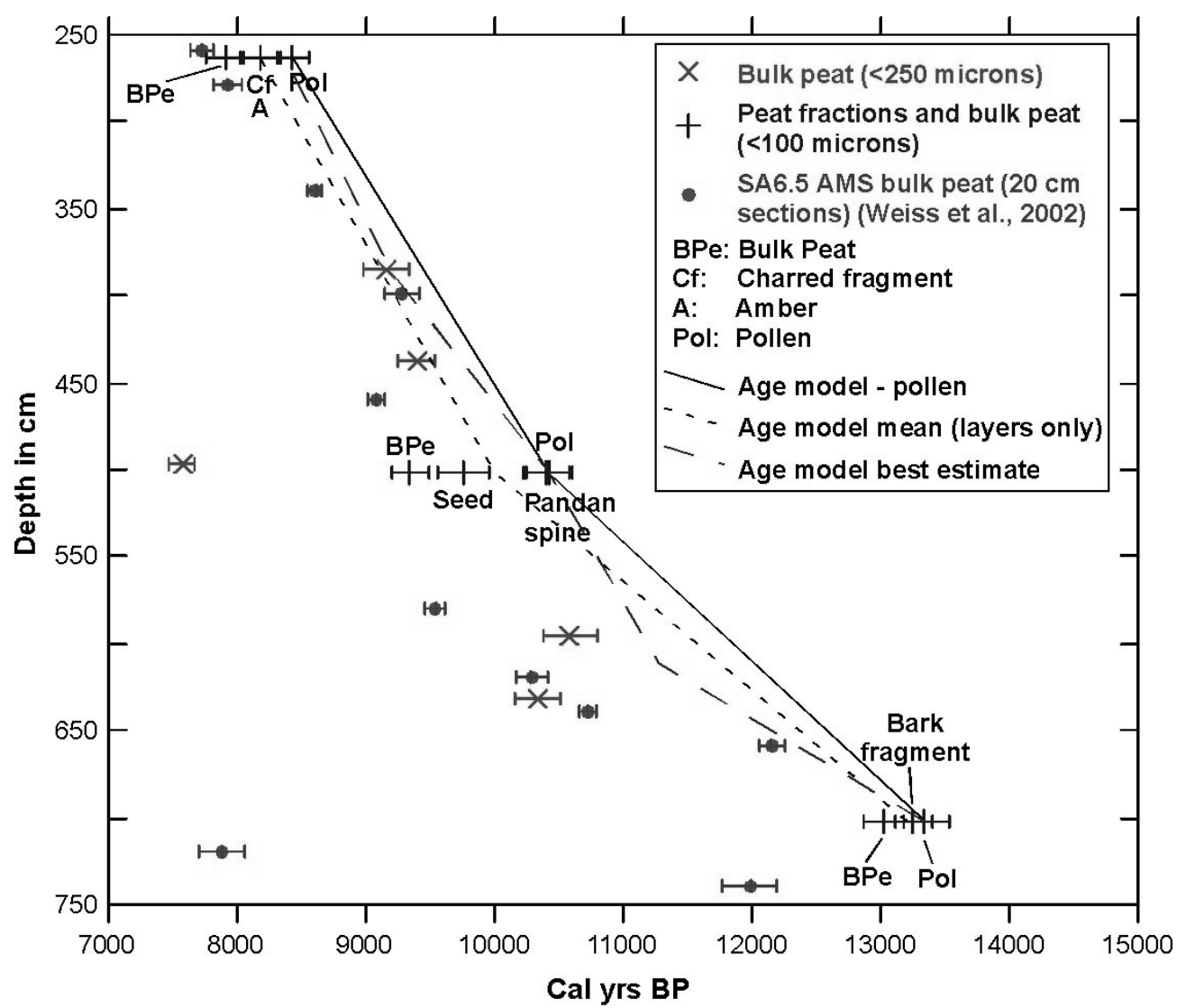

Figure 4 Details of the central core sections $\left(250-750 \mathrm{~cm}\right.$ depth) of the ${ }^{14} \mathrm{C}$ ages of all data from the Kal- 1 core (Table 1) and core SA6.5 of Weiss et al. (2002) with hypothetical age models (e.g. based on pollen, mean, and best estimate).

Three possible age models are proposed in order to discuss sample types with tropical peats and their dating investigations. All models show distinct differences. The pollen model assumes that the pollen extract is the "true" age of the layers (i.e. represents the time of the peat layer formation at the surface). The resulting linear (between individual pollen dates) model shows that the bulk samples and the other individual fractions are all younger than the pollen model curve (Figure 4). A second age model was constructed based on the "average age" of the individual fractions, and this model shows that some bulk samples (between $350-450 \mathrm{~cm}$ depth) yield ages that would represent "older" ages (e.g. age inversions) than predicted by the model. Both these models assume linear accumulation rates between the horizons. The third model, called "best estimate," represents a model under which the accumulation rates were not linear. This model is based on the fact that several bulk samples between $580-650 \mathrm{~cm}$ depth yield similar or slightly older ages than the samples at $500 \mathrm{~cm}$ depth. In this case, it could be argued that the accumulation rate was slow between 13,500 and 
$\sim 11,000 \mathrm{cal} \mathrm{BP}$ and then significantly accelerated. This analysis suggests that age determination of tropical peat profiles would require a high resolution in the order of a few tens of $\mathrm{cm}$ in order to construct a confident age model.

\section{DISCUSSION}

Selecting appropriate fractions for ${ }^{14} \mathrm{C}$ measurements is critical for determining reliable age models, as has been demonstrated in several studies. In particular, lake sediments contain a wealth of fractions that may have large age differences (e.g. Björck et al. 1998; Xu and Zheng 2003; Oswald et al. 2005), making it difficult to evaluate what fraction will best represent the age of the layer. In peat environments, the selection of the appropriate organic fraction is no less difficult. In a study from the British Isles (Shore et al. 1995), 4 neighboring cores were analyzed and age variations $>1200 \mathrm{yr}$ were reported. For temperate cold peat environments, it has been proposed that Sphagnum plant fragments should be used for obtaining the most reliable ${ }^{14} \mathrm{C}$ ages (Nilsson et al. 2001) because of the large age differences between other fractions. However, in another study from Iceland, a Carex peat deposit with distinct tephra layers was used to test a range of alkali concentrations during pretreatment, but the different chemical pretreatments revealed only small age differences between the samples (Cook et al. 1995).

This study is the first investigation of the significance of various peat fractions of tropical peat deposits from Indonesia that are occupied by tall rainforest vegetation and exhibit large root bioturbation. The deposits initiated over 33,000 cal BP ago (Figures 2 and 4) but accumulation changed markedly during the LGM when climate conditions were too dry and/or too highly seasonal to sustain a high water table, thus limiting organic matter decomposition (Wüst et al. 2007). These conditions changed shortly after 14,000 cal BP ago when increased precipitation led to renewed peat accumulation. Accumulation rates were high $(\sim 1 \mathrm{~mm} / \mathrm{yr})$ during the early Holocene but slowed after the middle Holocene.

The large subsurface root inputs of tropical peats raises the key question: What "fraction" is most representative of the age? It is generally assumed that the ${ }^{14} \mathrm{C}$ age of a layer represents the "past surface" age of the material. This assumption may well be valid for slowly accumulating peat systems with mosses where degradation is high but may not be true for systems where accumulation rates are high $(>0.7 \mathrm{~mm} / \mathrm{yr})$ with substantial subsurface root input. There, younger carbon addition in the subsurface may affect the true "surface" age of the peat material. Hence, the selection of the organic fraction for dating is critical for the age model of the entire peat deposit. Several important findings have been revealed by our study of ${ }^{14} \mathrm{C}$ AMS dating of individual peat fraction from tropical Kalimantan:

1. In all 4 layers (sample depths: $263-265,500-504,702-705,864-867 \mathrm{~cm}$ ), the pollen extracts provided the oldest ${ }^{14} \mathrm{C}$ age (Figure 3, Table 1), although in the central layers the age difference between the other fractions and the pollen extract was minimal $(\sim 10-20 \mathrm{yr})$ and statistically insignificant with respect to the standard deviation. The resultant hypothetical pollen extract age model (Figure 4) would contain little if any age inversion.

2. In most layers, the bulk material represented the youngest ${ }^{14} \mathrm{C}$ age (Figure 3). This fraction often contains high amounts of rootlets and carbonized rootlets most likely from younger plant material (Figure 1). It is interesting, however, that the bulk samples, whether sieved at $100 \mu \mathrm{m}$ or $250 \mu \mathrm{m}$ (and those from core SA6.5), produce a reasonably well-constrained age model (Figure 2).

3. The ${ }^{14} \mathrm{C}$ ages of the uppermost 3 layers $(263-265,500-504,702-705 \mathrm{~cm})$, which are older than 7000 but younger than $12,000{ }^{14} \mathrm{C}$ yr, show discrepancies between the individual fractions that 
range from 10 up to $900{ }^{14} \mathrm{C} \mathrm{yr}$ (Table 1, Figure 3). This section of the peat profile developed under an almost uniform fast accumulation rate of 1.2-2.2 mm per yr (Wüst et al. 2007). Most fractions have a ${ }^{14} \mathrm{C}$ age difference that is very small, either within the standard deviation or only $100-200{ }^{14} \mathrm{C}$ yr. The exception is the bulk fractions. In general, all fractions show older ages than the bulk samples, including the $<250-\mu \mathrm{m}$ fraction or the bulk samples from core SA6.5 from the previous studies (Table 1, Figure 4).

4. The lowest layer $(866 \mathrm{~cm})$ exhibited the greatest discrepancies of ${ }^{14} \mathrm{C}$ ages, and the variation between bark and pollen extract was $>16,000{ }^{14} \mathrm{C}$ yr. This basal section was deposited before the LGM. During the LGM, there was a hiatus of peat accumulation, during which time the peat deposit may have experienced a high degree of humification and may have been disturbed by bioturbation, resulting in large age ranges (Figure 2). During the LGM, the environment was most likely forested, but due to reduced precipitation and/or stronger seasonality, little net carbon accumulation occurred except for the subsurface root input. Net peat accumulation started again $\sim 14,000$ cal BP ago (Figure 2) (i.e. deposition of the upper $8 \mathrm{~m}$ of peat), at a depth of $\sim 805 \mathrm{~cm}$. This large time span of little to no peat growth allowed younger material $(\sim 10,000$ 14,000 cal BP old) to be mixed with the older strata (pre-LGM, possible even post-LGM). The bulk material of the deposit at depths $>805 \mathrm{~cm}$ represents a mixture of old (Pleistocene/preLGM) and young (late Pleistocene/early Holocene) organic material. The changes in sedimentation rate are reflected in the "best estimate" age model (Figure 4). It is interesting to note that the bark fragment exhibits a much younger age. If bioturbation were solely responsible for the introduction of such younger material, one would expect to see similar mixing with the pollen or bulk material. The AMS data of the bulk samples at $>805 \mathrm{~cm}$ depth (see all $<100 \mu \mathrm{m},<250$ $\mu \mathrm{m}$, and SA6.5 samples, Figure 2) somehow reflect this mixing (possibly due to root input) of pre-LGM and Late Pleistocene material. The pollen data, however, do not support the idea of thorough mixing. It is hypothesized that the bulk material represents mainly younger root input into an older peat matrix, while the bark may have been derived from a larger branch that dropped down and was buried into the peat rather than through a slow and continuous mixing process.

The study reveals some important issues that are characteristic of many ${ }^{14} \mathrm{C}$-dated Holocene deposits, but in particular for tropical peat deposits: What is regarded as the optimal organic fraction to be dated? And what does "optimal" imply? Does the "optimal" sediment age date refer to the material deposited at the former peat surface or at a homogenous minimal mixing? Since tropical peats are complex organic deposits, the use of a term such as "best" or "optimal" age may in fact be misleading despite the fact that the ages may be compared to another dating technique. For example, in some peat deposits, tephra or siliciclastic sediment layers are present and can help to furnish an age control or at least a point of reference (e.g. Brown et al. 1992). Detailed investigations into this issue have been done in peat/lake sediments from New Zealand (Vandergoes and Prior 2003; Newnham et al. 2007). There, ${ }^{14} \mathrm{C}$ dates of pollen concentrates from peat and lake sediments were correlated to data of the Kawakawa tephra. Those data showed that the lake sediments yielded comparative data to the tephra but that the pollen extracts of peat deposits were exclusively younger by up to several thousand years both above and below the tephra layer. Unfortunately, none of the many Holocene tropical peat deposits in Malaysia and Indonesia has a confirmed tephra layer-or at least a geochemical anomaly layer that could be used as a volcanic marker layer (i.e. Weiss et al. 2002; Wüst and Bustin 2004), despite the fact that abundant active volcanoes occur in Indonesia. The lack of ash layers could be due to the acidic conditions ( $\mathrm{pH} \sim 3.5-5$ ) or the low nutrient status of the peatlands, which could lead to rapid uptake of airborne minerals by the vegetation. 
Our study shows that selection of the organic fraction of tropical peats is critical for ${ }^{14} \mathrm{C}$ age determination. Although this has been demonstrated before in temperate peat deposits (Shore et al. 1995; Nilsson et al. 2001), this study demonstrated that $\mathrm{AMS}{ }^{14} \mathrm{C}$ ages of the various organic fractions can be significantly different in tropical peatlands where organic matter accumulation can be very fast (up to $2 \mathrm{~mm} / \mathrm{yr}$ ) or contains evidence of changes in climatic conditions and/or vegetation composition (i.e. fast peat growth or stagnant/negative growth when organic matter oxidation is equal or exceeds organic matter production). This is particularly true for root mass input as tropical rainforest can have root penetrations that exceed $2 \mathrm{~m}$ depth.

Bulk peat sample age determination is a common practice as isolating, pretreating, and dating individual fractions can be more time consuming and expensive. In our study, we assumed that the finest organic material represents the "most degraded" organic material formed at the surface (or at least in shallow subsurface) during aeration (acrotelm layer) of the organic material. The $100-\mu \mathrm{m}$ size was used as bulk fraction in this study because investigations in 2005 showed that the $<250-\mu \mathrm{m}$ fraction still contained abundant and long micro-rootlets and charred rootlets. A former study argued that some of the charred rootlets originate from in situ burnt rootstocks caused by tree fires (lightning) during low water table levels during the intermonsoon season (Wüst and Bustin 2004). That study dated a charcoal fragment in a Malaysian peat deposit from $148 \mathrm{~cm}$ depth to $270 \mathrm{cal} \mathrm{BP}$; the age would imply a peat accumulation rate of $>5 \mathrm{~mm} / \mathrm{yr}$, which is $\sim 10-30$ times higher than the average accumulation rate in that area. In the peat samples from Kalimantan, carbonized rootlets (Figure 1) are abundant, and some of these may have been derived from in situ tree fires. Therefore, we argue that in tropical peat deposits, charcoal material may not represent an ideal fraction for determining the age structure due to deeply penetrating rootlets, occasional tree fires, and large water table fluctuations.

Our study shows that the bulk peat material yields younger ages than most of the macrofossil fractions (Figures 2,3). This implies that the fine material $(<100 \mu \mathrm{m})$ contains components of various ages and the age range between fractions of the same layers can be large (several thousand years, see e.g. Figure 3). The resulting age model using the mean of all layers (Figure 4) may not be fully satisfactory as a few bulk samples would yield age inversions. Similarly, a study from temperate peat deposits using fine and bulk fractions also showed mixed results (Nilsson et al. 2001). For example, several fine fraction $(<45 \mu \mathrm{m})$ samples produced ${ }^{14} \mathrm{C}$ ages younger than those of the bulk material. However, in tropical peats, finer "bulk" fractions (i.e. $<32 \mu \mathrm{m}$ ) than used in this study may lead to the exclusion of most long rootlets and therefore may represent ideal material for dating the timing of the "former" surface, but this would need to be tested in future approaches.

Overall, the study shows that probably the best materials for dating tropical peat deposits are pollen extracts. It is possible that the pollen extract fraction may represent an age that is slightly older than the "true" surface deposition because pollen grains are small and may artificially migrate upward in the profile as a result of bioturbation and/or the fluctuating groundwater table in the acrotelm (e.g. Clymo and Mackay 1987). Our study does not disclose or exclude this, but some fractions (i.e. pandan spine at 500-504 cm and bark at 702-705 cm depth) have almost identical ages as the pollen fractions that may indicate that little pollen migration occurred in the profile. Unfortunately, the age model cannot be tested by independent tephra dating as no ash layers were observed. However, none of the bulk samples fall to the right of the pollen age model (Figure 4), indicating no age inversion. For future work, a high-resolution age analysis of the pollen record would be desirable to support the hypothesis that the pollen fraction is the best material for the dating of tropical peat deposits. 


\section{CONCLUSIONS}

This study investigated the use of different organic fractions for ${ }^{14} \mathrm{C}$ dating of tropical peat deposits. Four different depth layers, spanning the last $28,000{ }^{14} \mathrm{C}$ yr, were analyzed and the fractions compared to other bulk sample data. The results indicate that the pollen extracts produced exclusively the oldest dates, while the bulk samples $(<250 \mu \mathrm{m}$ and $<100 \mu \mathrm{m})$ often yielded the youngest ages. The age difference between the individual fractions depended on the layer depth and the age of the peat material. The discrepancies between the ages were highest $\left(\sim 16,000{ }^{14} \mathrm{C} \mathrm{yr}\right)$ in the oldest peat material, which received input of organic matter over a long period of time due to negative or no peat accumulation during the LGM period. In the Holocene deposits, age discrepancies were smaller up to $900{ }^{14} \mathrm{C}$ yr, but in some cases less than the standard deviation. The study concludes that the pollen extract fraction, although the most time consuming and expensive to prepare, apparently represents the most suitable fraction for dating tropical peat deposits that are covered by deeply rooting vegetation.

\section{ACKNOWLEDGMENTS}

This study was supported through through a Merit Research Grant from James Cook University (RW) and 2 grants from the Australian Institute for Nuclear Science and Engineering (AINGRA 06/ 200, AINGRA 05/175). We would also like to thank Ms Ursula Pietrzak for performing the pollen separations. Comments of 2 anonymous reviewers greatly improved this manuscript.

\section{REFERENCES}

Anshari G, Kershaw AP, van der Kaars S, Jacobsen G. 2004. Environmental change and peatland forest dynamics in the Lake Sentarum area, West Kalimantan, Indonesia. Journal of Quaternary Science 19(7):63755.

Björck S, Bennike O, Possnert G, Wohlfarth B, Digerfeldt G. 1998. A high-resolution ${ }^{14} \mathrm{C}$ dated sediment sequence from southwest Sweden: age comparisons between different components of the sediment. Journal of Quaternary Science 13(1):85-9.

Blackford J. 2000. Palaeoclimatic records from peat bogs. Trends in Ecology \& Evolution 15(5):193-8.

Brown TA, Farwell GW, Grootes PM, Schmidt FH. 1992. Radiocarbon AMS dating of pollen extracted from peat samples. Radiocarbon 34(3):550-6.

Casagrande DJ, Erchull LD. 1977. Metals in plants and waters in the Okefenokee swamp and their relationship to constituents found in coal. Geochimica et Cosmochimica Acta 41(9):1391-4.

Clymo RS, Mackay D. 1987. Upwash and downwash of pollen and spores in the unsaturated surface layer of Sphagnum-dominated peat. New Phytologist 105(1): $175-83$.

Cook GT, Dugmore AJ, Shore JS. 1998. The influence of pretreatment on humic acid yield and ${ }^{14} \mathrm{C}$ age of Carex peat. Radiocarbon 40(1):21-7.

Fairbanks RG Mortlock RA, Chiu T-C, Cao L, Kaplan A, Guilderson TP, Fairbanks TW, Bloom AL, Grootes PM, Nadeau M-J. 2005. Radiocarbon calibration curve spanning 0 to 50,000 years BP based on paired ${ }^{230} \mathrm{Th} /{ }^{234} \mathrm{U} /{ }^{238} \mathrm{U}$ and ${ }^{14} \mathrm{C}$ dates on pristine corals. Qua- ternary Science Reviews 24(16-17):1781-96.

Flessa KW, Cutler AH, Meldahl KH. 1993. Time and taphonomy: quantitative estimates of time-averaging and stratigraphic disorder in a shallow marine habitat. Paleobiology 19(2):266-86.

Goh KM. 1978. Removal of contaminants to improve the reliability of radiocarbon dates of peats. European Journal of Soil Science 29(3):340-9.

Gupta SK, Polach HA. 1985. Dating material and pretreatment of samples. In: Radiocarbon Dating Practices at ANU. Canberra: Radiocarbon Dating Laboratory, Research School of Pacific Studies, ANU. p 827.

Hedges REM. 1992. Sample treatment strategies in radiocarbon dating. In: Taylor RE, Long A, Kra RS, editors. Radiocarbon After Four Decades. New York: Springer-Verlag; Tucson: Radiocarbon. p 165-83.

Hua Q, Jacobsen GE, Zoppi U, Lawson EM, Williams AA, McGann MJ. 2001. Progress in radiocarbon target preparation at the ANTARES AMS Centre. Radiocarbon 43(2A): 275-82.

Hua Q, Zoppi U, Williams AA, Smith AM. 2004. Smallmass AMS radiocarbon analysis at ANTARES. $\mathrm{Nu}$ clear Instruments and Methods in Physics Research B 223-224:284-92.

Kummel B, Raup D. 1965. Handbook of Paleontological Techniques. San Francisco: WH Freeman. 852 p.

Newnham RM, Vandergoes MJ, Garnett MH, Lowe DJ, Prior C, Almond PC. 2007. Test of AMS ${ }^{14} \mathrm{C}$ dating of pollen concentrates using tephrochronology. Journal of Quaternary Science 22(1):37-51. 
Nilsson M, Klarqvist M, Bohlin E, Possnert G. 2001. Variation in ${ }^{14} \mathrm{C}$ age of macrofossils and different fractions of minute peat samples dated by AMS. The Holocene 11(5):579-86.

Oswald WW, Anderson PM, Brown TA, Brubaker LB, Hu FS, Lozhkin AV, Tinner W, Kaltenrieder P. 2005. Effects of sample mass and macrofossil type on radiocarbon dating of arctic and boreal lake sediments. The Holocene 15(5):758-67.

Page SE, Wüst RAJ, Weiss D, Rieley JO, Shotyk W, Limin SH. 2004. A record of Late Pleistocene and Holocene carbon accumulation and climate change from an equatorial peat bog (Kalimantan, Indonesia): implications for past, present and future carbon dynamics. Journal of Quaternary Science 19(7):625-35.

Reimer PJ, Baillie MGL, Bard E, Bayliss A, Beck JW, Bertrand CJH, Blackwell PG, Buck CE, Burr GS, Cutler KB, Damon PE, Edwards RL, Fairbanks RG, Friedrich M, Guilderson TP, Hogg AG, Hughen KA, Kromer B, McCormac G, Manning S, Bronk Ramsey C, Reimer RW, Remmele S, Southon JR, Stuiver M, Talamo S, Taylor FW, van der Plicht J, Weyhenmeyer CE. 2004. IntCal04 terrestrial radiocarbon age calibration, 0-26 cal kyr BP. Radiocarbon 46(3):1029-58.

Rieley JO, Ahmad-Shah AA, Brady MA. 1996. The extent and nature of tropical peat swamps. In: Maltby E, Immirzi CP, Safford RJ, editors. Tropical Lowland Peatlands of Southeast Asia. Gland, Switzerland: International Union for Conservation of Nature. p 1754.

Ruppert L, Neuzil S, Cecil C, Kane J. 1993. Inorganic constituents from samples of a domed and lacustrine peat, Sumatra, Indonesia. In: Cobb JC, Cecil CB, editors. Modern and Ancient Coal-Forming Environments. Boulder, Colorado, USA: Geological Society of America, Special Paper. p 83-97.

Sarmaja-Korjonen K, Kultti S, Solovieva N, Väliranta M. 2003. Mid-Holocene palaeoclimatic and palaeohydrological conditions in northeastern European Russia: a multi-proxy study of Lake Vankavad. Journal of Paleolimnology 30(4):415-26.

Shore JS, Bartley DD, Harkness DD. 1995. Problems encountered with the ${ }^{14} \mathrm{C}$ dating of peat. Quaternary Science Reviews 14(4):373-83.

Shotyk W. 1988. Review of the inorganic geochemistry of peats and peatland waters. Earth-Science Reviews 25(2):95-176

Shotyk W, Weiss D, Appleby PG, Cheburkin AK, Frei R, Gloor M, Kramers JD, Reese S, van der Knaap WO.
1998. History of atmospheric lead deposition since $12,370{ }^{14} \mathrm{C}$ yr BP from a peat bog, Jura Mountains, Switzerland. Science 281(5383): 1635-40.

Smith AM, Petrenko VV, Hua Q, Southon J, Brailsford G. 2007. The effect of $\mathrm{N}_{2} \mathrm{O}$, catalyst, and means of water vapor removal on the graphitization of small $\mathrm{CO}_{2}$ samples. Radiocarbon 49(2):245-54.

Telford RJ, Heegaard E, Birk HJB. 2004. All age-depth models are wrong: but how badly? Quaternary Science Reviews 23(1):1-5.

Vandergoes MJ, Prior CA. 2003. AMS dating of pollen concentrates-a methodological study of late Quaternary sediments from south Westland, New Zealand. Radiocarbon 45(3):479-91.

Weiss D, Shotyk W, Rieley J, Page S, Gloor M, Reese S, Martinez-Cortizas A. 2002. The geochemistry of major and selected trace elements in a forested peat bog, Kalimantan, SE Asia, and its implications for past atmospheric dust deposition. Geochimica et Cosmochimica Acta 66(13):2307-23.

Wüst RAJ, Bustin RM. 2003. Opaline and Al-Si phytoliths from a tropical mire system of West Malaysia: abundance, habit, elemental composition, preservation and significance. Chemical Geology 200(3-4): 267-92.

Wüst RAJ, Bustin RM. 2004. Late Pleistocene and Holocene development of the interior peat-accumulating basin of tropical Tasek Bera, Peninsular Malaysia. Palaeogeography, Palaeoclimatology, Palaeoecology 211(3-4):241-70.

Wüst RAJ, Rieley J, Page S, van der Kaars S, Wei-Ming W, Jacobsen G, Smith A. 2007. Peatland evolution in Southeast Asia during the last 35,000 years: implications for evaluating their carbon storage potential. In: Rieley JO, Banks CJ, Radjagukguk B, editors. Carbon-Climate-Human Interaction on Tropical Peatland. Proceedings of the International Symposium and Workshop on Tropical Peatland, Yogyakarta, 27-29 August 2007, EU CARBOPEAT and RESTORPEAT Partnership, Gadjah Mada University, Indonesia and University of Leicester, United Kingdom. p 19.

Xu S, Zheng G. 2003. Variations in radiocarbon ages of various organic fractions in core sediments from Erhai Lake, SW China. Geochemical Journal 37:135-44.

Zhou W, Xie S, Meyers PA, Zheng Y. 2005. Reconstruction of late glacial and Holocene climate evolution in southern China from geolipids and pollen in the Dingan peat sequence. Organic Geochemistry 36(9): $1272-84$. 